\title{
Incidence and costs of hip fractures compared to acute myocardial infarction in the Italian population: a 4-year survey
}

\author{
P. Piscitelli • G. Iolascon • F. Gimigliano • M. Muratore • \\ P. Camboa • O. Borgia • B. Forcina $\cdot$ F. Fitto $\cdot$ \\ V. Robaud • G. Termini • G. B. Rini • E. Gianicolo • \\ A. Faino • M. Rossini • S. Adami - A. Angeli • \\ A. Distante $\cdot$ S. Gatto $\cdot$ R. Gimigliano $\cdot$ G. Guida $~$ \\ on the behalf of the SIOMMMS study group \\ and the CERSUM research group
}

Received: 7 November 2005 / Accepted: 28 August 2006 / Published online: 24 October 2006

(C) International Osteoporosis Foundation and National Osteoporosis Foundation 2006

\begin{abstract}
Introduction Few data are available about the incidence and costs of hip fractures in Italy. We aimed to determine the impact of hip fractures vs. acute myocardial infarction (AMI).

Methods We studied the national hospitalization database to calculate their incidence and costs in adults aged $\geq 45$ between 1999 and 2002 .
\end{abstract}

\footnotetext{
P. Piscitelli $(\bowtie)$

University of Pisa, ISBEM Research Center,

Brindisi, Italy

e-mail: prisco.piscitelli@tiscali.it

G. Iolascon • F. Gimigliano $\cdot$ S. Gatto $\cdot$ R. Gimigliano $\cdot$ G. Guida

Department of Orthopaedic Surgery and Traumatology,

Second University of Naples,

Naples, Italy

M. Muratore

Local Health Authority AUSL Lecce/1,

Lecce, Italy

P. Camboa $\cdot$ O. Borgia

Local Health Authority AUSL Lecce/2,

Maglie, Italy

F. Fitto

Department of Orthopaedic Surgery, Città di Lecce Hospital,

Lecce, Italy

V. Robaud

National Committee for Biosecurity and Biotechnologies,

Biorisks Group,

Rome, Italy
}

Results In 2002, there were 86,719 hip fractures with a $10.0 \%$ increase over 4 years. We observed a predominance of women $(77.1 \%)$ and a strong age effect: $92.7 \%$ of patients were $\geq 65$ years old and $80 \%$ of fractures occurred in women aged $\geq 75$, showing a clear relationship with the incidence of osteoporosis. Hospitalizations due to AMI after 45 years of age in 1999 were only 9\% higher than those for hip fracture, although this difference increased

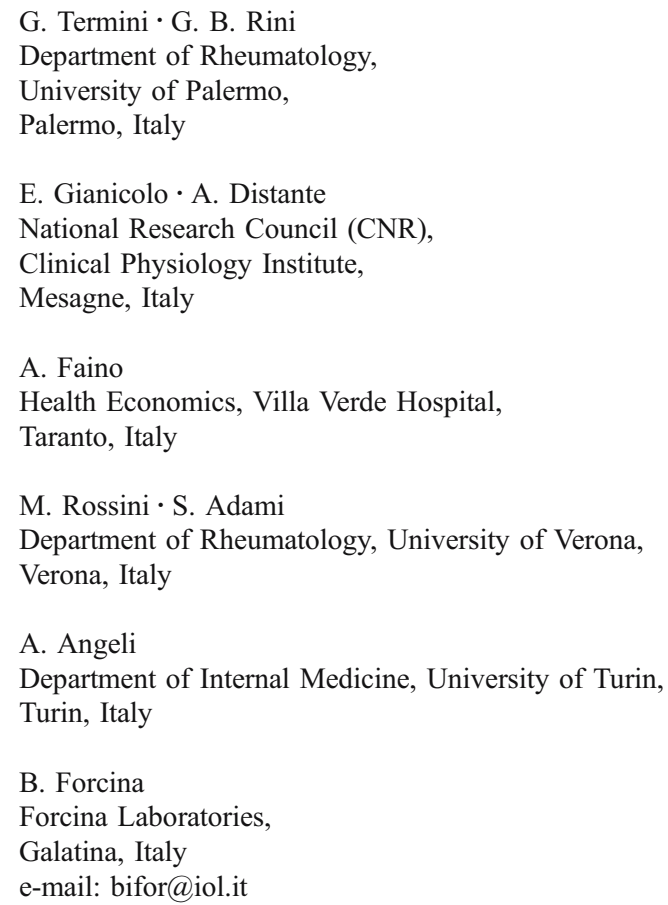


over the 4 examined years up to $24 \%$. Considering the DRGs costs, hip fractures resulted in being more expensive than AMI overall and concerning elderly people.

Conclusions This study shows that in the Italian population aged $\geq 45$, hospitalizations following hip fracture and AMI between 1999 and 2002 were comparable, while hip fractures' direct costs were higher and grew faster than costs for AMI. Hip fractures in Italy are a serious medical problem and a leading health-cost driver.

Keywords Aging · AMI $\cdot$ Costs $\cdot$ Epidemiology .

Hip fractures $\cdot$ Incidence

\section{Introduction}

Demographic trends of the last 50 years have increased life expectancy and changed the age profile of populations in developed countries. Italy has one of the highest life expectancies in the world: according to the Italian National Institute for Statistics (ISTAT), life expectancy at birth increased at a rate of 4 months per year from 1950 to 2002, reaching 76.2 years for men and 82.6 years for women [1]; life expectancy is estimated to rise to 77.9 and 84.4 years, respectively, by 2010 [1]. High life expectancy combined with low natality has increased the weight of older age groups within the general population, such that Italy represents an interesting international case study for aging-related diseases. In Italy, $18 \%$ of the population is actually over 65 years of age; within the next decade, this age group may exceed $22 \%$ of the population [2]. Moreover, $4 \%$ of this group is already $\geq 80$ years of age [1]. Increased life expectancy is associated with a greater frailty of elderly people and a higher prevalence of chronic and degenerative diseases. Osteoporosis and its complications - especially hip fractures-represent a challenge for health professionals and decision makers in the 21st century. The World Health Organization (WHO) considers osteoporosis to be second only to cardiovascular diseases as a critical health problem [3]. The Epidemiological Study on the Prevalence of Osteoporosis in Italy (ESOPO) reported a high prevalence of osteoporosis in 2000: $23 \%$ among all women, with age-specific rates ranging from $9 \%$ (40 to 49 year olds) to $45 \%$ (70 to 79 year olds), and almost $15 \%$ in men aged $\geq 60$ years [5].

Thus, we estimate that in Italy 4 million women and 800 thousand men are exposed to an increased risk of fracture, as shown by several studies [6-13]. The International Osteoporosis Foundation (IOF) estimated that, worldwide, hip fractures will occur in $18 \%$ of women and $6 \%$ of men, while $33 \%$ of women and $11 \%$ of men aged $\geq 80$ years will experience a hip fracture due to osteoporosis [3, 4]. Hip fractures require a longer period of hospitalization than all other pathologies, with the only exception of psychiatric diseases [14]. In developed countries, mortality from hip fractures is greater than that from gastric and pancreatic cancer; at the same time, the risk of experiencing a hip fracture is higher than that of developing breast, endometrial and ovarian cancer in women or prostatic cancer in men [3]. The current mortality following hip fractures is similar to that for breast cancer, with a $5 \%$ acute mortality rate that increases to $15-25 \%$ within 1 year $[2,6,15]$. Once hip fracture has occurred, the ability to walk is completely lost in $20 \%$ of cases, and only $30-40 \%$ of patients recover a degree of autonomy comparable to the period before the fracture [2, 15-19]. Each year in Italy, almost 18,000 persons become completely disabled as a consequence of hip fractures, resulting in inestimable human suffering and substantial social costs [2]. Despite these observations, no detailed data are available about the incidence and costs of hip fractures in the elderly Italian population, demonstrating a worrisome lack of appreciation concerning the severity of this pathology. Therefore, we carried out a detailed study to evaluate the impact of hip fractures in Italy in terms of incidence and costs. Furthermore, our intention was to perform a comparison analysis with a different pathology whose severity is well appreciated by healthcare operators and the public. As comparator, we chose acute myocardial infarction (AMI) because it can be considered as emblematic for cardiovascular diseases (the worldwide leading critical health problem according to WHO, as cited above). Like hip fractures, AMI has multiple risk factors and a high prevalence among the general population; it is expected to produce high healthcare costs, and preventive measures represent a critical issue as for hip fractures.

\section{Materials and methods}

We studied the impact of hip fractures, in comparison to acute myocardial infarction (AMI), in the Italian population aged 45 years and older, in the 4-year period 1999-2002. We included persons between 45 and 65 years of age as well as elderly subjects because we expected the incidence and costs of AMI to be high in this younger subgroup. The study period was chosen because it reflects the most recently available nationwide clinical and demographic data. Population data were obtained from the National Institute for Statistics (ISTAT) for each of the considered years: in 2002 , there were $25,055,775$ adults $\geq 45$ years of age [1].

Analysis of epidemiological trends

Clinical data were obtained from the national hospitalization database (SDO) maintained by the Italian Ministry of 
Health. National hospitalization records are the best possible surrogate to reflect the true incidence of hip fractures in the population. Hip fractures were defined by the following ICD-9CM diagnosis codes: 820.0-820.1 (femoral head fractures), 820.2-820.3 (inter-trochanteric femoral fractures) and 820.8-820.9 and 821.1 (other femoral fractures). AMI was defined by code 410 and all subcodes. Data on incidence and hospital stay were stratified by gender and into three age groups (45-64, 65-74 and $\geq 75$ years) and were processed using Stata (StataCorp, College Station, USA) and Excel (Microsoft, Redmond, USA) software. We performed descriptive statistical analyses of the incidence in each gender and age subgroup across the 4 examined years.

\section{Hospitalization direct costs analysis}

Analysis of direct costs was based on the costs ascribed to diagnosis-related groups (DRGs), according to the Ministerial Decree DM 549 of 30 June 1997. This decree contains the national DRG rate list adopted during the 4 years examined in our study. However, the Italian system allows each region to drop the DRG value at the local level. The average reduction adopted is about $15 \%$. Therefore, in the present analysis, we used the 1997 DRG rates reduced by $15 \%$ in order to be more conservative. DRGs considered relevant to hip fractures were: 209 (surgical procedures on major joints and hip replacement), 210-211 (hip and femur surgery) and 235-236 (hip, femur or pelvis fractures). Because not all patients assigned these DRGs had a main diagnosis of hip fracture (i.e., osteoarthritis accounts for a substantial number of hip replacements), we asked the Ministry of Health to determine the percentage of costs due to hip fracture for each DRG. The analysis was performed for patients living in Lazio (including Rome), a region with 5.3 million inhabitants, an aging index comparable to the national average [1] and a number of large hospital and orthopedic centers. The information provided by the Ministry of Health was consistent with the findings we obtained on a smaller sample of almost 1 million people assisted by two local health authorities (Lecce/1 and Lecce/2). According to this analysis performed by the Ministry of Health, 30\% of costs ascribed to DRG 209 and $80 \%$ of costs ascribed to DRGs 210, 211, 235 and 236 were attributable to a main diagnosis of hip fracture. We considered these rates to represent the weight of hip fracture-related costs for each DRG.

Cost analysis for AMI included all DRGs that specified this pathology: both medical and surgical ones. Medical DRGs (including costs due to fibrinolysis or thrombolysis) were the following: DRG 121 (cardiovascular diseases with AMI and cardiovascular complications, patient alive), DRG 122 (cardiovascular diseases with AMI without cardiovas- cular complications, patient alive), DRG 123 (cardiovascular diseases with AMI leading to death) and DRG 124 (cardiovascular diseases with AMI, treated by cardiac catheterization and leading to complications). All patients assigned to these medical DRGs presented a main diagnosis of AMI. Surgical DRGs included in order to consider percutaneous coronary interventions or coronary bypass were the following: DRG 107 (by-pass) and DRG 112 (percutaneous interventions/angioplasty). The Ministry of Health provided us with the percentage of costs resulting from AMI for the surgical DRGs considered (actually not all patients assigned these DRGs had a main diagnosis of AMI, i.e., unstable angina accounts for a substantial number of these procedures). As previously, this information was based on the population of the Lazio region (including Rome) as a significant sample and was confirmed on the smaller sample of 1 million people assisted by local health authorities Lecce/1 and Lecce/2. This analysis revealed that only $1 \%$ of DRG 107 and $15 \%$ of DRG 112 overall costs were related to a main diagnosis of AMI. The analysis of direct costs was conducted assuming that the length of hospitalization for hip fractures and AMI did not exceed the average values calculated in the DRG rates. Direct costs were evaluated for all patients ( $\geq 45$ years of age), as well as for elderly patients ( $\geq 65$ years).

Rehabilitation and indirect costs estimation

Although our study intended to focus on hospitalization costs, because they could be more accurately measured thanks to the availability of institutional databases (i.e., hospitalization records), we have also provided an estimation attempt of rehabilitation costs and indirect costs following hip fractures and AMI. For elderly patients with hip fractures, we considered indirect costs associated with postoperative rehabilitation, disability pensions and overhead. According to the latest Italian study [23], the average cost for 1 month of postoperative rehabilitation, after adjustment and conversion into the new Euro currency, is estimated to be 5,375 Euros per patient. Actually, the duration of the rehabilitation period following hip fractures according to the Italian law is 1 month, including rehabilitative interventions started during the hospitalization (usually the first 10-14 days) and their ambulatorial or home-based extension. We computed rehabilitation costs only for $95 \%$ of the patients, assuming that $5 \%$ die immediately after the surgical procedure [2, 6, 15]. For the estimated 18,000 patients who annually become disabled as a consequence of hip fracture [2], we considered a government-paid disability financial aid of 6,000 Euros per year, as provided according to the Italian law for disabled persons, corrected for the average yearly 
mortality rate for hip fractures $(15-25 \%)[2,6,15]$. The impact of all the other indirect costs related to hip fractures were estimated to account for $20 \%$ of overall direct costs, as suggested by the IOF [3].

The average duration of the rehabilitation period following AMI according to the Italian law is 21 days, including rehabilitative interventions started during the hospitalization and their ambulatorial or home-based extension. To assess rehabilitation costs following AMI, we have considered the rate fixed by Italian law for intensive rehabilitation activities (rate corresponding to code no. 56): 200 Euros per day. We computed rehabilitation costs only for $85 \%$ of the patients, assuming a $15 \%$ acute mortality rate following AMI [24, 25]. Diagnosis of AMI alone (excluding severe complications, defined by other ICD-9CM diagnosis codes) is usually not considered by the Italian law as a condition leading to the recognition of disability financial aid, and it was not the aim of this study to evaluate costs of AMI complications or those related to other cardiovascular diseases. Indirect costs related to AMI are difficult to evaluate, but they could represent up to the double the overall direct costs $[25,26]$.

\section{Results}

The total number of hip fractures in Italy and the average hospitalization days among adults $\geq 45$ years of age was 78,834 in 1999 and 86,719 in 2002, corresponding to an increase of $10.0 \%$ over 4 years (Table 1). Considering all 4 years together, the majority of hip fractures occurred in patients 65 years of age or older $(93.1 \%)$ and particularly in women $(77.1 \%)$. Among women, $79.2 \%$ of fractures were experienced in patients $\geq 75$ years of age. The number of fractures in this subgroup of women increased by $12.8 \%$ over 4 years and accounted for most (77.0\%) of the observed increase in total hip fractures between 1999 and
2002. In the same period, hip fractures in men aged $\geq 75$ years increased by $16.0 \%$ to 13,582 . The mean duration of hospitalization ranged from 14.0 to 16.7 days for all age and gender categories in each year examined. These data verified our methodological assumption for the analysis of costs that the actual hospital stay did not exceed the allowed values of DRGs. Breakdown by age and gender (Table 3) confirmed the marked increase with age and the predominance of women, whose incidence was more than twice that of men for the two older age groups. The temporal increase in hip fracture incidence from 1999 to 2002 is evident in the oldest age group (for both genders). In 2002, the incidence of hip fractures in people aged 75 years and over was 185.0 per 10,000 persons for women and 84.9 for men.

Tables 2 and 3 show the total number and the average hospitalization days due to AMI in Italy among adults $\geq 45$ years of age between 1999 and 2002. Table 4 shows the incidence of AMI per 10,000 inhabitants between 1999 and 2002. In the same Italian population aged $\geq 45$ years, acute myocardial infarction (AMI) resulted in the hospitalization of 86,100 patients in 1999 and 106,842 patients in 2002 , corresponding to an increase of $24.0 \%$ over 4 years. The number of hospitalizations due to AMI in men approximates the number of hospitalizations for hip fractures in women; therefore, in 1999, AMI resulted only in 7,266 more hospitalizations than hip fractures (a difference of 9\%); in the years 2000, 2001 and 2002, AMI resulted in 9,846 (11\%), 13,425 (16\%) and 20,123 (23\%) additional hospitalizations, respectively, compared to hip fractures. Considering only elderly persons, direct costs of hospitalization for hip fractures were $>40 \%$ higher than those for AMI in each year analyzed. Overall direct costs for hip fractures and AMI in the period 1999-2002 were determined as the sum of the weighted costs for each DRG. Direct costs for hip fractures increased by $22.3 \%$ from 417 to 510 million Euros (Table 5). Elderly people $\geq 65$ years

Table 1 Number of hip fractures and average duration of hospitalization in Italy during 1999-2002, by age and gender

\begin{tabular}{|c|c|c|c|c|c|c|c|c|}
\hline \multirow[t]{2}{*}{ Age group } & \multicolumn{2}{|l|}{1999} & \multicolumn{2}{|l|}{2000} & \multicolumn{2}{|l|}{2001} & \multicolumn{2}{|l|}{2002} \\
\hline & Men & Women & Men & Women & Men & Women & Men & Women \\
\hline \multicolumn{9}{|l|}{ 45-64 years } \\
\hline Fractures, $\mathrm{n}$ & 2,520 & 3,633 & 2,527 & 3,259 & 2,550 & 3,584 & 2,510 & 3,405 \\
\hline Hospitalization, days & 15.4 & 14.4 & 14.5 & 14.4 & 14.1 & 14.2 & 14.2 & 14.0 \\
\hline \multicolumn{9}{|l|}{$65-74$ years } \\
\hline Fractures, $\mathrm{n}$ & 3,573 & 9,854 & 3,611 & 9,589 & 3,716 & 9,618 & 3,715 & 9,879 \\
\hline Hospitalization, days & 16.3 & 16.2 & 16.4 & 16.0 & 16.0 & 15.7 & 16.0 & 15.3 \\
\hline \multicolumn{9}{|l|}{$\geq 75$ years } \\
\hline Fractures, $\mathrm{n}$ & 11,702 & 47,552 & 12,426 & 47,867 & 13,153 & 51,867 & 13,582 & 53,628 \\
\hline Hospitalization, days & 15.9 & 16.7 & 16.0 & 16.6 & 15.9 & 16.2 & 15.6 & 15.7 \\
\hline Total fractures, $\mathrm{n}$ & 17,795 & 61,039 & 18,564 & 60,715 & 19,419 & 65,069 & 19,807 & 66,912 \\
\hline Average hospitalization days & 15.90 & 15.61 & 15.87 & 16.38 & 15.68 & 16.01 & 15.49 & 15.55 \\
\hline
\end{tabular}


Table 2 Number of AMI and average duration of hospitalization in Italy during 1999-2002, by age and gender

\begin{tabular}{|c|c|c|c|c|c|c|c|c|}
\hline \multirow[t]{2}{*}{ Age group } & \multicolumn{2}{|l|}{1999} & \multicolumn{2}{|l|}{2000} & \multicolumn{2}{|l|}{2001} & \multicolumn{2}{|l|}{2002} \\
\hline & Men & Women & Men & Women & Men & Women & Men & Women \\
\hline \multicolumn{9}{|l|}{$45-64$ years } \\
\hline AMI, n & 25,220 & 4,646 & 25,357 & 4,765 & 27,359 & 5,279 & 28,594 & 5,673 \\
\hline Hospitalization, days & 8.95 & 9.53 & 8.55 & 9.12 & 8.15 & 8.72 & 7.63 & 8.26 \\
\hline \multicolumn{9}{|l|}{$65-74$ years } \\
\hline AMI, n & 17,519 & 7,838 & 17,996 & 7,925 & 18,909 & 8,637 & 20,109 & 9,149 \\
\hline Hospitalization, days & 9.70 & 9.82 & 9.31 & 9.43 & 9.29 & 9.73 & 8.80 & 9.44 \\
\hline \multicolumn{9}{|l|}{$\geq 75$ years } \\
\hline AMI, n & 14,830 & 16,047 & 15,917 & 17,195 & 18,234 & 19,495 & 20,804 & 22,513 \\
\hline Hospitalization, days & 10.52 & 10.83 & 10.18 & 10.51 & 9.82 & 10.31 & 9.62 & 10.17 \\
\hline Total AMI, $\mathrm{n}$ & 57,569 & 28,531 & 59,240 & 29,885 & 64,502 & 33,411 & 69,507 & 37,335 \\
\hline Average hospitalization days & 9.58 & 10.34 & 9.22 & 10.00 & 8.95 & 9.90 & 8.56 & 9.69 \\
\hline
\end{tabular}

old accounted for approximately $80 \%$ of the total costs for hip fracture; for these patients, costs increased by $15.5 \%$ over the 4 years. Direct costs for hospitalization following AMI (Table 5) increased by $2.5 \%$ from 400 to 410 million Euros; in elderly patients, costs increased by $12.0 \%$ over the 4 years. Overall, these data indicate that in the 4 years examined, the costs associated with hospitalization for hip fractures were higher and increased faster than costs for AMI.

Although the objective of the study was to determine incidence and hospitalization costs as the primary endpoint, we report in Tables 6 and 7 the estimations of other costs not related to hospitalization. The results of these secondary analyses may contribute to a full evaluation of costs generated by hip fractures and AMI, which also requires a consideration of costs due to rehabilitation, disability pensions and indirect costs. It should be pointed out that rehabilitation costs following both hip fractures and AMI are comparable to those of hospitalization. Therefore, the analysis of 2002 data for elderly subjects revealed that total direct and indirect costs for hip fractures in Italy exceeded 1 billion Euros.

\section{Discussion}

This study aimed to measure more appropriately the impact of hip fractures in Italy by analyzing data archived in the national hospitalization database. Although the national hospitalization records represent the best possible surrogate of the true incidence, a very small number of hip fractures may not result in hospitalization. It is important to point out the assumption that all hip fractures were considered in this analysis, independently of underlying osteoporosis or not; no osteoporosis attribution rates were applied, and it was impossible to exclude readmissions for a same person. However, the most frequent underlying cause of hip fractures in the elderly (which represent the majority of cases recorded in the hospitalization database) is osteoporosis. As expected, $79.2 \%$ of fractures were experienced in patients 75 years of age or older, in accordance with the higher prevalence of osteoporosis in this age class [5].

Compared to acute myocardial infarction, the number of hospitalizations for hip fracture was 9\% less in 1999 and $23 \%$ less in 2002; this change is partially due to the $24.0 \%$ increase in hospitalizations for AMI, attributable not only to a greater incidence, but also to the establishment throughout

Table 3 Incidence of hip fractures per 10,000 inhabitants in Italy (1999-2002), stratified by gender and age class

\begin{tabular}{|c|c|c|c|c|c|c|c|c|}
\hline & \multicolumn{2}{|l|}{1999} & \multicolumn{2}{|l|}{2000} & \multicolumn{2}{|l|}{2001} & \multicolumn{2}{|l|}{2002} \\
\hline & Men & Women & Men & Women & Men & Women & Men & Women \\
\hline $45-64$ years & 3.6 & 4.9 & 3.7 & 4.5 & 3.2 & 4.9 & 3.5 & 4.7 \\
\hline Growth vs. prior year & & & $+2.8 \%$ & $-8.2 \%$ & $-13.5 \%$ & $+8.9 \%$ & $+9.4 \%$ & $-4.1 \%$ \\
\hline $65-74$ years & 13.6 & 30.1 & 13.9 & 29.8 & 14.2 & 29.7 & 14.2 & 30.4 \\
\hline Growth vs. prior year & & & $+2.2 \%$ & $-1.0 \%$ & $+2.2 \%$ & $-0.3 \%$ & $0.0 \%$ & $+2.4 \%$ \\
\hline$\geq 75$ years & 72.8 & 163.9 & 77.9 & 165.8 & 82.2 & 178.9 & 84.9 & 185.0 \\
\hline Growth vs. prior year & & & $+7.0 \%$ & $+1.2 \%$ & $+5.5 \%$ & $+7.9 \%$ & $+3.3 \%$ & $+3.4 \%$ \\
\hline
\end{tabular}


Table 4 Incidence of AMI per 10,000 inhabitants in Italy (1999-2002), stratified by gender and age class

\begin{tabular}{|c|c|c|c|c|c|c|c|c|}
\hline & \multicolumn{2}{|l|}{1999} & \multicolumn{2}{|l|}{2000} & \multicolumn{2}{|l|}{2001} & \multicolumn{2}{|l|}{2002} \\
\hline & Men & Women & Men & Women & Men & Women & Men & Women \\
\hline $45-64$ years & 35.70 & 6.30 & 35.90 & 6.47 & 38.73 & 7.16 & 40.48 & 7.70 \\
\hline Growth vs. prior year & & & $+0.6 \%$ & $+2.7 \%$ & $+7.9 \%$ & $+10.7 \%$ & $+4.5 \%$ & $+7.5 \%$ \\
\hline $65-74$ years & 66.85 & 24.16 & 68.67 & 24.43 & 72.15 & 26.62 & 76.73 & 28.20 \\
\hline Growth vs. prior year & & & $+2.7 \%$ & $+1.1 \%$ & $+5.1 \%$ & $+9.0 \%$ & $+6.3 \%$ & $+5.9 \%$ \\
\hline$\geq 75$ years & 92.65 & 55.35 & 99.44 & 59.31 & 113.92 & 67.25 & 129.98 & 77.66 \\
\hline Growth vs. prior year & & & $+7.3 \%$ & $+7.2 \%$ & $+14.6 \%$ & $+13.4 \%$ & $+14.1 \%$ & $+15.5 \%$ \\
\hline
\end{tabular}

the country (in the year 2000) of an effective emergency service capable of preventing many of the acute deaths that previously occurred before the hospital admission. Direct costs of hospitalization following hip fracture were higher than those for AMI and increased at a greater rate over the 4 years examined. This is easily explained because most of the DRGs considered for AMI represent medical DRGs (including fibrinolysis), which cost much less than surgical DRGs. Surgical DRGs related to AMI (i.e., PCI, BCGA, etc.) were fewer than those for hip fractures (always requiring surgical procedures). Concerning AMI, the number of patients hospitalized is lower than the real incidence because sudden mortality is expected to be quite relevant. However, this study was focused on hip fractures, and AMI was studied in comparison as a pathology whose severity is generally well perceived. It was not our aim to determine the incidence of AMI in the general population, including sudden deaths, which do not lead to hospitalization; however, this could not have caused an underestimation of the number of hospitalizations and the direct cost analysis. Other cardiovascular ischemic diseases, such as unstable angina pectoris, were not included in the analysis because they are classified in different ICD9CM codes and also because they frequently require ambulatory treatment, which is not the object of this analysis. However, although direct costs of hospitalization due to hip fractures are higher than those of AMI, the overall costs of the two pathologies (if considering rehabilitation costs and indirect costs) may be comparable as described in Tables 6 and 7 .

Our findings seem to be consistent with IOF estimates of the overall incidence and costs of hip fractures in Italy [3] and provides further detailed information regarding the costs specifically generated by elderly people. Furthermore, our findings are consistent with the national hospitalization database analysis concerning surgical aspects (the number of operations due to hip fractures) [27] and with data from other European countries [28-31] and from the United States [32-34], confirming the high social impact of hip fractures despite a worrisome lack in the perception of its severity [35]. Compared to our estimate of 1 billion Euros in Italy, the reported costs of osteoporotic fractures in other countries are (in US dollars) 2 billion for Canada and Australia [3, 34, 36], 31 billion in the United States [3, 32] and 17 billion in EU countries [3]. This Italian study is of special interest because it has been carried out using the national hospitalization database; thus, the data reported are more detailed values rather than simple estimates. According to the commonly accepted approach in health economics, we used DRGs in calculating direct costs because this permitted us to measure the financial consequences of hospitalization. However, the Italian DRG system has changed since the last national law of 1997, and now the

Table 5 Total direct costs of hospitalization for hip fractures and acute myocardial infarction (AMI excluding unstable angina pectoris), 19992002 , for all adults ( $\geq 45$ years) and for the elderly ( $\geq 65$ years). Values are expressed in millions of Euros

\begin{tabular}{|c|c|c|c|c|c|c|}
\hline & \multicolumn{2}{|l|}{ Adults } & \multirow{2}{*}{$\begin{array}{l}\text { Relative growth difference } \\
\text { between hip fr. and AMI }\end{array}$} & \multicolumn{2}{|l|}{ Elderly } & \multirow{2}{*}{$\begin{array}{l}\text { Relative growth difference } \\
\text { between hip fr. and AMI }\end{array}$} \\
\hline & Hip fracture & AMI & & Hip fracture & AMI & \\
\hline 1999 & 417 & 400 & & 341 & 241 & \\
\hline 2000 & 442 & 402 & & 343 & 243 & \\
\hline Growth vs. previous year & $+6.0 \%$ & $+0.5 \%$ & $+5.5 \%$ & $+0.6 \%$ & $+0.8 \%$ & $-0.2 \%$ \\
\hline 2001 & 480 & 408 & & 373 & 251 & \\
\hline Growth vs. previous year & $+8.6 \%$ & $+1.5 \%$ & $+7.1 \%$ & $+8.7 \%$ & $+3.3 \%$ & $+5.4 \%$ \\
\hline 2002 & 510 & 410 & & 394 & 270 & \\
\hline Growth vs. previous year & $+6.3 \%$ & $+0.5 \%$ & $+5.8 \%$ & $+5.6 \%$ & $+7.6 \%$ & $-2.0 \%$ \\
\hline
\end{tabular}


Table 6 Overall estimated costs for the 80,804 hip fractures registered in Italian elderly persons ( $\geq 65$ years of age) in 2002

\begin{tabular}{llll}
\hline & Patients, $\mathrm{n}$ & $\begin{array}{l}\text { Unit cost, } \\
\text { Euros }\end{array}$ & Cost \\
\hline $\begin{array}{l}\text { Hospitalization costs } \\
\text { Rehabilitation }\end{array}$ & 80,804 & $\mathrm{NA}$ & 394 million \\
$\begin{array}{l}(1 \text { month) } \\
\text { Disability pension }\end{array}$ & $18,764^{\mathrm{a}}$ & 5,375 & 412 million \\
$\begin{array}{l}\text { Indirect costs } \\
\text { Total }\end{array}$ & $\mathrm{NA}$ & $\mathrm{NA}$ & 108 million \\
& & & 161 million \\
& & & 1,075 \\
\hline
\end{tabular}

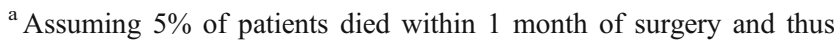
not beginning rehabilitation;

${ }^{\mathrm{b}}$ Based on $20 \%$ of direct costs (hospitalization and rehabilitation) NA, not applicable

20 regions may establish their own rates, cutting off the DRGs values at the local level. Accepting a $15 \%$ average reduction for each DRG allowed us to estimate a mean value in order to overcome the differences between the regions. The costs of rehabilitation in this study may be underestimated. We chose to consider only 1 month of postoperative rehabilitation because this is the average duration provided by the law, including the rehabilitative interventions performed at the hospital (usually 10 14 days of postoperative hospitalization days), even though not all patients comply with the rehabilitation program afterwards [37]. As suggested by the IOF [3], we considered that indirect costs due to overhead equalled $20 \%$ of the overall direct costs, even though many authors have suggested that these costs are higher than hospitalization costs $[28,30,33,34]$. Finally, we estimated the cost for disability financial aid paid by the state to persons who become fully disabled (recognition of disability $\geq 75 \%$ ) after hip fracture, taking in account that some of them

Table 7 Overall estimated costs for the 72,575 AMI registered in Italian elderly persons ( $\geq 65$ years of age) in 2002

\begin{tabular}{|c|c|c|c|}
\hline & Patients, $\mathrm{n}$ & $\begin{array}{l}\text { Unit cost, } \\
\text { Euros }\end{array}$ & Cost \\
\hline Hospitalization costs & 72,575 & NA & 270 million \\
\hline $\begin{array}{l}\text { Rehabilitation } \\
\text { (1 month) }\end{array}$ & 61,688 & 200 & 260 million \\
\hline Disability pension & NA & NA & NA \\
\hline Indirect costs ${ }^{\mathrm{b}}$ & NA & NA & 530 million \\
\hline Total & & & $\begin{array}{l}1,060 \\
\text { million }\end{array}$ \\
\hline
\end{tabular}

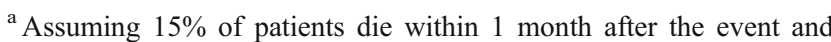
thus do not begin rehabilitation;

${ }^{b}$ Assuming the hypothesis of indirect costs being up to the double of direct costs

NA, not applicable
}

$(15 \%-25 \%)$ die within a year $[2,6,15]$. The cost estimates related to disability pensions following hip fractures are conservative: actually the entire annual sum paid as social aid may exceed 7,500 Euros per patient. We also have to consider that although the Italian law does not provide financial aid to people who have experienced AMI, its potential complications such as chronic hearth failure may result in the acknowledgment of a disability pension (but only if the disease is very severe, because of the adoption of more conservative criteria by the health authorities concerning cardiovascular diseases).

A complete analysis of the phenomenon would also require data regarding intangible costs associated with hip fractures, such as costs due to pain, lack of productivity, premature mortality, a reduction in the quality of life and social suffering. An Italian analysis reviewed by the Italian Senate Health Commission in 2002 [2] indicated that patients and their relatives lose 364,000 working days per year because of hip fractures, resulting in a high economic impact estimated as 1.7 billion Euros. Like rehabilitation costs and indirect costs, intangible costs are also difficult to measure and were not the aim of this study; therefore, they were not assessed. The increasing incidence of hip fracture is ascribed mainly to elderly women, in accordance with the higher prevalence of osteoporosis in the oldest age groups. This study reveals the urgent necessity of adopting preventive measures to reduce the incidence and costs of osteoporosis-related hip fractures, which continue to be considered as a secondary health problem. Although our data have demonstrated similar incidences and costs between hip fractures and AMI in Italy, the overall Italian expenditures for pharmacological treatments aimed to reduce the risk of hip fractures in 2001 represented just $0.29 \%$ (almost 46 million Euros) of the national drug expenditures [2]. In the same year, total expenditures for cardiovascular drugs represented $32 \%$ of the total [2]. Other measures to prevent hip fractures could be the promotion of healthy lifestyles and physical activity and the use of hip protectors [38-44]. Further studies, including pharmaeconomic simulations, should determine if the adoption of proper preventive measures (not exclusively pharmacological ones) in high-risk patients (i.e., people with previous vertebral fractures and patients taking corticosteroid drugs) can decrease the incidence of hip fractures without a major impact on general costs. In Sweden, economic simulations [45] have already documented that fracture-preventive treatments are more cost-effective than common cardiovascular preventive strategies (e.g., treating hypertension for the prevention of stroke). Ethical considerations about the right of elderly people to live with an adequate quality of life make it urgent to find appropriate answers to agingrelated health problems like hip fractures, which are increasing year by year in developed countries. 


\section{Conclusion}

This study shows that in the Italian adult population ( $\geq 45$ years) the number of hospitalizations following hip fracture and AMI are comparable, while direct costs of hospitalization following hip fracture were higher than those for AMI and grew faster for all the 4 years examined. These findings were based on a comparison of data issued from a unique source and when applying similar methods of analysis. This observation held when we focused on elderly persons, as well as when we considered all adults aged $\geq 45$ years and thus included the age class with the highest incidence of AMI (45-65 years). Therefore, hip fractures in Italy are a serious medical problem and a leading health cost driver, consistent with what has already been reported for many other countries in the industrialized world.

Acknowledgments This study was funded and promoted by Second University of Naples (SUN). We thank Prof. M.L. Brandi (SIOMMMS President) for supporting our study group; we are grateful to Dr. L. Lispi and D. Del Gigante (General Direction for Planning Affairs, Italian Ministry of Health) for their help in the analysis of national hospitalization data. Many thanks to Senator L. Compagna (Parliamentary Commission for Education, University and Scientific Research) and to Commission XII (Public Health) of the Italian Senate. We are also grateful to Dr. G. D'Alò, Dr. R. Giorgino and Dr. W. Meier for all the indications that allowed the beginning of this study in 2002. Special acknowledgments go to Dr. F. Gnagnarella (LUM Jean Monnet, Bari), Prof. F. P. Calamo Specchia (Catholic University of Rome) and the CERSUM research group on osteoporosis, whose members are: G. Gaeta, L. Di Paola, G. Chitano and M. Benvenuto (Euro Mediterranean Scientific Biomedical Institute, ISBEM/IFC CNR, Brindisi). Other members of the SIOMMMS study group on epidemiological topics of femoral fractures are: Dr. Eugenio Quarta (AUSL Lecce1, Lecce), Dr. Giovanni Scuderi (AUSL Trapani/1), Dr. Fabio Di Salvo (SANICAM, Palermo), Dr. Guido Siciliano (University of Catania), Dr. Vito Martorana (CTO Palermo), Dr. Antonietta Matina (Palermo University Hospital), Dr. Carmela Sferrazza (Palermo University Hospital), Dr. Nicola Napoli (Palermo University Hospital), Dr. Andrea Dovio (University of Turin), Prof. Giulia Letizia (University of Palermo).

\section{References}

1. -(2002) Annuario statistico italiano, 2002. National Institute for Statistics, Rome

2. Italian Senate Health Commission (eds) (2002) Official Report of the Survey on Osteoporosis. Italian Senate, Rome

3. Osteoporosis in the European Community: a call for action. International Osteoporosis Foundation, Lyon (2002)

4. Cooper C, Campion G, Melton LJ 3rd (1992) Hip fractures in the elderly: a world-wide projection. Osteoporos Int 2:285

5. Adami S, Giannini S, Giorgino R et al (2003) The effect of age, weight, and lifestyle factors on calcaneal quantitative ultrasound: the ESOPO study. Osteoporos Int 14:198-207

6. Browner WS, Pressman AR, Nevitt MC, Cummings SR (1996) Mortality following fractures in older women. The study of osteoporotic fractures. Arch Intern Med 156:1521-1525
7. Lindsay R, Silverman SL, Cooper C et al (2001) Risk of new vertebral fracture in the year following a fracture. JAMA 285:320-323

8. Ismail AA, O’Neill TW, Cooper C et al (1998) Mortality associated with vertebral deformity in men and women: results from the European Prospective Osteoporosis Study (EPOS). Osteoporos Int 8:291-297

9. Pluijm SM, Tromp AM, Smit JH et al (2000) Consequences of vertebral deformities in older men and women. J Bone Miner Res 15(8):1564-1572

10. Center JR, Nguyen TV, Schneider D et al (1999) Mortality after all major types of osteoporotic fracture in men and women: an observational study. Lancet 353(9156):878-882

11. Kado DM, Browner WS, Palermo L et al (1999) Vertebral fractures and mortality in older women. Arch Intern Med 159:1215-1220

12. Cauley JA, Thompson DE, Ensrud KC et al (2000) Risk of mortality following clinical fractures. Osteoporosis Int 11:556-561

13. Meyer HE, Tverdal A, Falch JA, Pedersen JI (2000) Factors associated with mortality after hip fracture. Osteoporos Int $11: 228-232$

14. Papaioannou A, Adachi JD, Parkinson W et al (2001) Lengthy hospitalization associated with vertebral fractures despite control for comorbid conditions. Osteoporos Int 12:870-874

15. Keene GS, Parker MJ, Pryor GA (1993) Mortality and morbidity after hip fractures. BMJ 307:1248-1250

16. Hagsten B et al (2006) Health-related quality of life and selfreported ability concerning ADL and IADL after hip fracture: a randomized trial. Acta Orthop 77(1):114-119, Feb

17. Di Monaco M et al (2006) Muscle mass and functional recovery in women with hip fracture. Am J Phys Med Rehabil 85(3):209215, Mar

18. Zimmermann S et al (2006) The lower extremity gain scale: a performance-based measure to assess recovery after hip fracture. Arch Phys Med Rehabil 87(3):430-436, Mar

19. Latham NK (2006) Pattern of functional change during rehabilitation of patients with hip fracture. Arch Phys Med Rehabil 87 (1):111-116, Jan

20. Eisenstein EL et al (2001) Assessing the clinical and economic burden of coronary artery disease: 1986-1998. Med Care 39 (8):824-835, Aug

21. Jonsson B et al (2001) The effects of cardiac events on quality of life and indirect costs. J Hum Hypertens 15(Suppl 1):S91-S93, Aug

22. Riggs BL, Melton LJ 3rd (1995) The worldwide problem of osteoporosis: insights afforded by epidemiology. Bone 17(5 Suppl):505S-511S

23. Visentin P, Ciravegna R, Fabris F (1997) Estimating the cost per avoided hip fracture by osteoporosis treatment in Italy. Maturitas 26:185-192

24. Vaccarino et al (1999) Sex-based differences in early mortality after myocardial infarction. N Engl J Med 341:217-225

25. Tu JV (2003) Introduction to the Canadian Cardiovascular Outcomes Research Team's (CCORT) Canadian Cardiovascular Atlas project. Can J Cardiol 19(3):225-229, Mar 15

26. Thom $T$ et al (2006) Heart disease and stroke statistics-2006 update. A report from the american heart association statistics committee and stroke statistics subcommittee circulation. 113: e 85

27. Piscitelli P, Iolascon G, Guida G et al (2005) Femoral fractures and orthopaedic surgery in Italy. J Orthopaed Traumatol 6:202-205

28. Autier P, Haentjens P, Bentin J et al (2000) Costs induced by hip fractures: a prospective controlled study in Belgium. Belgian Hip Fracture Study Group. Osteoporosis Int 11:373-380

29. Lippuner K, von Overbeck J, Perrelet R et al (1997) Incidence and direct medical costs of hospitalizations due to osteoporotic fractures in Switzerland. Osteoporos Int 7:414 
30. Dolan P, Torgerson DJ (1998) The cost of treating osteoporosis fractures in the United Kingdom female population. Osteoporos Int 8:611-617

31. Johnell O, Gullberg B, Allander E, Kanis JA (1992) The apparent incidence of hip fracture in Europe: a study of national register sources. MEDOS Study Group. Osteoporos Int 2:298302

32. Ray NF, Chan JK, Thamer M, Melton LJ 3rd (1997) Medical expenditures for treatment of osteoporotic fractures in the United States in 1995: report from the National Osteoporosis Foundation. J Bone Miner Res 12(1):24-35

33. Johnell O (1997) The socioeconomic burden of fractures: today and in the 21st century. Am J Med 103:20S-25S; discussion $25 \mathrm{~S}-26 \mathrm{~S}$

34. Cooper C, Campion G, Melton LJ 3rd (1992) Hip fractures in the elderly: a worldwide projection. Osteoporos Int 2:285-289

35. Reginster J Y, The osteoporosis paradox: the neglected disease, Proceedings of a symposium held at the 2nd International Meeting on Social \& Economic Aspects of Osteoporosis \& Bone Disease in Liege, Belgium, (7 Dec 2000), International Osteoporosis Foundation (IOF), Lyon

36. Access Economics Report (eds) (2001) The burden of brittle bones: costing osteoporosis in Australia. Access Economics, Canberra

37. Rossini M, Piscitellli P et al (2005) Incidence and socioeconomic burden of hip fractures in Italy. Reumatismo 57(2):97-102
38. NIH Consensus Development Panel on Osteoporosis Prevention, Diagnosis and Therapy (2001) Osteoporosis prevention, diagnosis and therapy. JAMA 285(6):785-795

39. Royal College of Physicians (1999) Osteoporosis, clinical guidelines for prevention and treatment. Royal College of Physicians of London, London

40. Genant HK, Cooper C, Poor G et al (1999) Interim report and recommendations of the World Health Organization Task-Force for Osteoporosis. Osteoporos Int 10:259-264

41. Hodgson SF, Watts NB, Bilezikian JP et al (2001) American association of clinical endocrinologists 2001 medical guidelines for clinical practice for the prevention and management of postmenopausal osteoporosis. Endocr Pract 7:293-312

42. Kanis JA et al (2000) Comparison of the European and USA practice guidelines for Osteoporosis. Trends Endocrinol Metab 11 (1):28-32, Jan-Feb

43. Spierings AB (2003) Assessment of hip protectors and corresponding hip fracture risk using stress calculation in the femoral neck. Med Eng Phys 2005 Nov 3

44. Kannus P, Parkkari J, Niemi S et al (2000) Prevention of hip fracture in elderly people with use of a hip protector. N Engl J Med 343:1506-1513

45. Jonsson B, Christiansen C, Johnell O et al (1996) Costeffectiveness of fracture prevention in established osteoporosis. Scand J Rheumatol Suppl 103:30-38 